\title{
Insulin-like growth factor signaling regulates zebrafish embryonic growth and development by promoting cell survival and cell cycle progression
}

\author{
PJ Schlueter ${ }^{1}$, G Peng $^{2}$, M Westerfield ${ }^{2}$ and C Duan ${ }^{*, 1}$
}

\begin{abstract}
Although much is known about the global effects of insulin-like growth factor 1 receptor (IGF1R)-mediated signaling on fetal growth and the clinical manifestations resulting from IGF/IGF1R deficiencies, we have an incomplete understanding of the cellular actions of this essential pathway during vertebrate embryogenesis. In this study, we inhibited IGF1R signaling during zebrafish embryogenesis using antisense morpholino oligonucleotides or a dominant-negative IGF1R fusion protein. IGF1R inhibition resulted in reduced embryonic growth, arrested development and increased lethality. IGF1R-deficient embryos had significant defects in the retina, inner ear, motoneurons and heart. No patterning abnormalities, however, were found in the brain or other embryonic tissues. At the cellular level, IGF1R inhibition increased caspase 3 activity and induced neuronal apoptosis. Coinjection of antiapoptotic $b c / 2$-like mRNA attenuated the elevated apoptosis and rescued the retinal and motoneuron defects, but not the developmental arrest. Subsequent cell cycle analysis indicated an increased percentage of cells in G1 and a decreased percentage in S phase in IGF1R-deficient embryos independent of apoptosis. These results provide novel insight into the cellular basis of IGF1R function and show that IGF1R signaling does not function as an anteriorizing signal but regulates embryonic growth and development by promoting cell survival and cell cycle progression.
\end{abstract}

Cell Death and Differentiation (2007) 14, 1095-1105. doi:10.1038/sj.cdd.4402109; published online 2 March 2007

The insulin-like growth factor (IGF) signaling pathway is an evolutionarily conserved signaling cascade that is essential for proper vertebrate growth and development. ${ }^{1-3}$ Activation of this critical pathway occurs when IGF ligands (IGF-1 and IGF-2) bind their cognate receptor tyrosine kinase, the IGF1 receptor (IGF1R). This leads to downstream activation of a number of signaling cascades, including mitogen-activated protein kinase and phosphatidylinositol 3-kinase. ${ }^{4}$ In vitro studies using a variety of mammalian cell lines, primary cultured cells and tissue explants have demonstrated that IGF1R signaling stimulates cell proliferation and protects cells from a variety of apoptotic stimuli. The mitogenic and antiapoptotic actions of IGF1R signaling are further underscored by the resistance of IGF1R-/- fibroblasts to malignant transformation. ${ }^{5}$

Clinical studies have shown that human patients with lossof-function mutations in either IGF-1 or the IGF1R suffer severe intrauterine growth restriction and poor postnatal growth, as well as microcephaly, deafness and mental retardation. $^{6-10}$ Mouse genetic studies further established the causational importance of IGF1R signaling in fetal growth and development. IGF1R null mutant mice exhibited severe growth retardation at birth (45\% of wild-type littermates) and died shortly after birth from respiratory failure. They also exhibited global organ hypoplasia and developmental retardation, with no loss of any organ or patterning abnormal- ities. $^{11,12}$ It has thus been concluded that IGF1R signaling is a central regulator of somatic growth in mammals.

Recent studies have shown that the major components of the IGF signaling pathway are conserved in lower vertebrates such as zebrafish. ${ }^{3}$ It was reported that zebrafish have two distinct igf1r genes resulting from a gene duplication event at the igf1r locus and both are required for embryonic viability and proper growth and development. ${ }^{13,14}$ Several studies in Xenopus, however, suggested that IGF1R signaling induces the formation of anterior neural tissue, the cellular basis for which was change in cell fate. ${ }^{15,16} \mathrm{~A}$ similar study in zebrafish was also reported. ${ }^{17}$ Thus, there is a major discrepancy concerning the cellular basis for the conserved IGF1R signaling cascade during vertebrate development.

In this study, we sought to investigate the developmental roles of IGF1R signaling during zebrafish embryogenesis and to elucidate the underlying cellular basis in vivo. We show that targeted knockdown or specific inhibition of IGF1R signaling resulted in reduced body size, retarded developmental rate and increased embryonic lethality. Despite the fact that IGF1R-deficient embryos had significant defects in the retina, inner ear, motoneurons and heart, no major patterning abnormalities were detected. We further provide evidence that the defects in retina and other neural tissues are primarily caused by elevated apoptosis, but the developmental arrest is

${ }^{1}$ Department of Molecular, Cellular and Developmental Biology, University of Michigan, Ann Arbor, MI, USA and ${ }^{2}$ Institute of Neuroscience, University of Oregon, Eugene, OR, USA

${ }^{*}$ Corresponding author: C Duan, Department of Molecular, Cellular and Developmental Biology, University of Michigan, Ann Arbor, MI 48109, USA. Fax: 734 647 0884; E-mail: cduan@umich.edu

Keywords: insulin-like growth factor 1 receptor; embryogenesis; retina; heart; cell cycle; apoptosis

Abbreviations: Bcl2, B-cell lymphoma 2; CaP, caudal primary motoneuron; dnIGF1R:GFP, dominant-negative insulin-like growth factor 1 receptor:green fluorescent protein; IGF, insulin-like growth factor; IGF1R, insulin-like growth factor 1 receptor; IMO, morpholino oligonucleotide

Received 20.6.06; revised 28.11.06; accepted 21.12.06; Edited by E Baehrecke; published online 02.3.07 
independent of apoptosis and correlates well with defects in cell cycle progression.

\section{Results}

Zebrafish igf1r knockdown causes growth retardation, developmental arrest and embryonic lethality but does not alter tissue patterning. To elucidate the roles of IGF1R signaling during zebrafish embryogenesis, the igf1r genes (igf1ra and igf1rb) were knocked down with gene-specific MOs. Two distinct igf1r MOs were designed to target each igf1r gene. The efficacy and specificity of these igf1r MOs in targeting their receptors were recently confirmed. ${ }^{13}$ In this study, we further verified the ability of these igf1r MOs to knockdown endogenous IGF1R proteins and inhibiting IGF1R signaling by biochemical analysis. As shown in Figure 1a, embryos injected with igf1r MOs have greatly reduced levels of total IGF1R protein compared to control MO-injected embryos. Further analysis showed a similar reduction in the levels of phosphorylated IGF1R (Figure 1b).

Previous work has shown that embryos with reduced IGF1R signaling exhibit significant reductions in both somite number and body length at $24 \mathrm{~h}$ postfertilization (hpf). ${ }^{13}$ In this study, we examined igf1r MO-injected embryos at multiple time points during the first $24 \mathrm{~h}$ of development (Figure 1c). Igfir MO-injected embryos developed normally until about $16 \mathrm{hpf}$. Their development slowed thereafter and arrested at approximately $18 \mathrm{hpf}$, whereas control MO-injected embryos continued to develop normally (Figure 1c). By $24 \mathrm{hpf}$, embryos

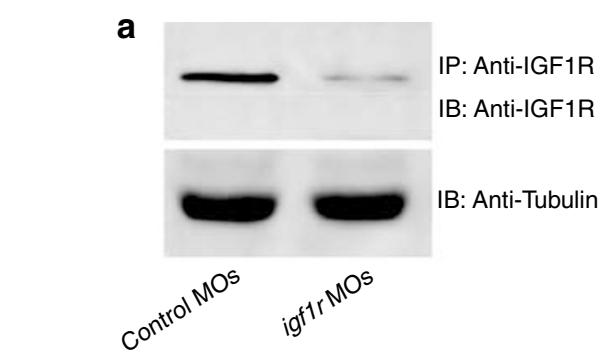

b
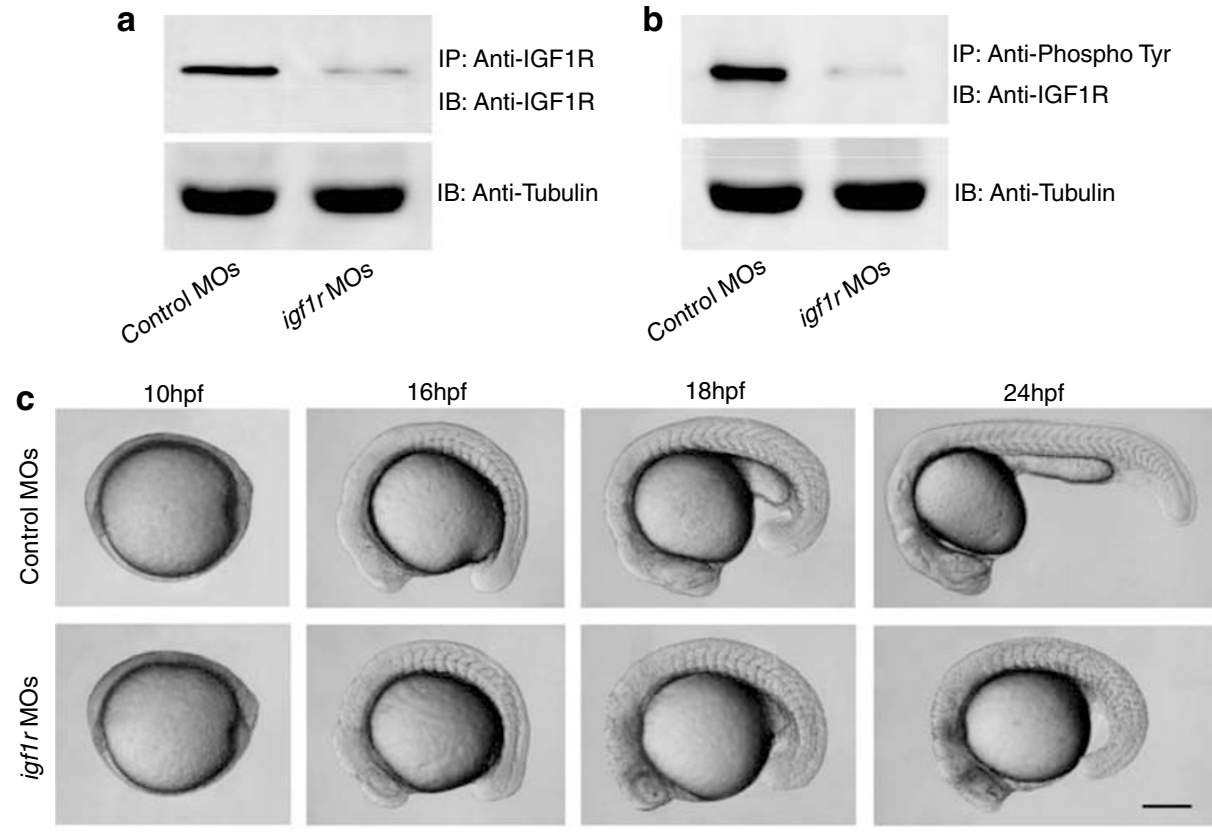

d
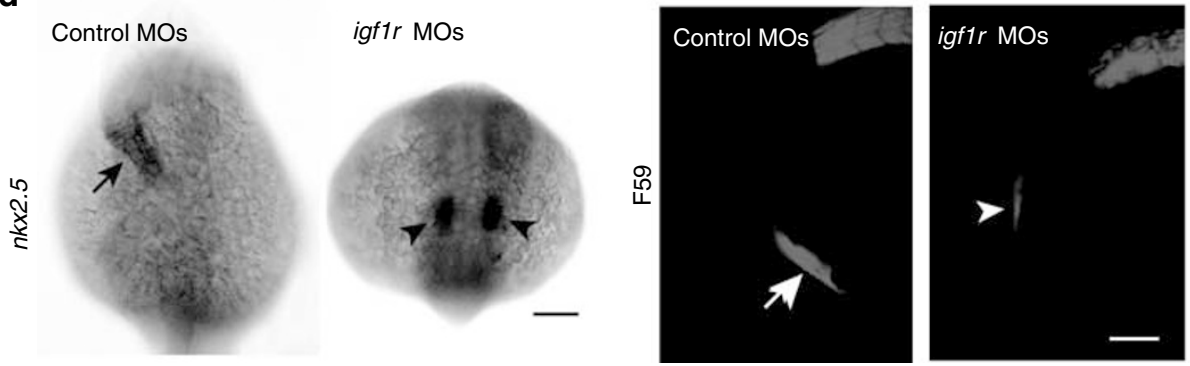

Figure 1 IGF1R signaling is required for the proper growth, development and survival of zebrafish embryos. (a, b) The effect of igf1r MOs in knocking down IGF1R protein and inhibiting IGF1R signaling was analyzed at $24 \mathrm{hpf}$ using IP followed by IB analysis. The antibodies used are indicated. An anti-Tubulin antibody was used to control for input and loading. Similar results were obtained in two other microinjection experiments. (c) Phenotypes of control (upper panels) and igf1r MO-injected embryos (lower panels) at 10, 16, 18 and $24 \mathrm{hpf}$. In three separate microinjection experiments, $78 \%$ of igf1r MO-injected embryos exhibited this phenotype $(N=210)$. Lateral views, anterior to the left. Scale bar $=250 \mu \mathrm{m}$. (d) Heart morphogenesis is retarded in igf1r MO-injected embryos compared to controls. Expression of $n k x 2.5 \mathrm{mRNA}$ in control and igf1r MOinjected embryos at $24 \mathrm{hpf}$ (left panels). Note the failure of the heart primordia in igftr MO-injected embryos (black arrowheads) to fuse at the dorsal midline to form a heart tube, as in controls (black arrow). Dorsal views, anterior to the top. Scale bar $=100 \mu \mathrm{m}$. Similar patterns were observed in all $12-15$ embryos examined in each group. F59 immunostaining in control and igf1r MO-injected embryos at $24 \mathrm{hpf}$ (right panels). Note the reduction in the cell mass and in ventral migration of the heart in igf1r MO-injected embryos (white arrowhead) compared to control MO-injected embryos (white arrow). Lateral views, anterior to the left, dorsal to the top. Scale bar $=100 \mu \mathrm{m}$. Similar patterns were observed in all embryos examined in each group $(N=12-15)$ 
injected with igf1rMOs had only $16.5+2.1$ somites compared to $29.8 \pm 1.3$ somites in the control group, indicating that they were developmentally equivalent to wild type or control embryos at 17-18 hpf. Additionally, igf1r MO-injected embryos lacked many anterior neuronal features, such as eyes and exhibited a lack of tissue transparency (Figure 1c). By 30 hpf (prim-15 stage), most igf1r MO-injected embryos died, whereas control MO-injected embryos were viable and morphologically indistinguishable from their wild-type siblings.

To investigate further this developmental arrest phenotype, we examined the timing of heart morphogenesis. In situ hybridization analysis of $n k x 2.5$ expression indicated that the heart primordia in igf1r MO-injected embryos failed to fuse at the dorsal midline even at $24 \mathrm{hpf}$ (Figure 1d). This pattern resembled that of wild type or control embryos at 17-18 hpf. ${ }^{18}$ Additionally, immunostaining with $\mathrm{F} 59$ for the ventriclespecific myosin heavy chain indicated that inhibition of IGF1R signaling resulted in a decrease in ventricle tissue and reduced migration of the heart toward the ventral side of the embryo (Figure 1d).

We next analyzed igf1r MO-injected embryos for potential patterning defects. We found that reduced IGF1R signaling did not alter brain patterning, as indicated by the mRNA expression of emx1 (labeling forebrain), eng2a (hindbrain), egr2 $b$ (third and fifth rhombomeres) and pax2a (optic stalk, mid-hindbrain boundary, hindbrain) (Figure $2 a-h)$, although the spatial domains of these markers were somewhat reduced in igf1r MO-injected embryos. The expression domains of myoD and myogenin were also reduced compared to controls (Figure $2 \mathrm{~m}-\mathrm{p}$ ). We also analyzed the expression of $r \times 1$ in the eye and claudin a in the otic vesicle and found the extent of expression to be more markedly reduced (Figure $2 \mathrm{i}-\mathrm{l}$ ).

To confirm that these defects found in igf1r MO-injected embryos are indeed caused by the loss of Igf1rs, MO-resistant mRNAs encoding full-length igf1ra and igf1rb were coinjected with igf1rMOs. As shown in Figure $3 a$, coinjection of the igf1r MOs along with igf1ra and igf1rb mRNA (igf1rmRNA) resulted in a significant recovery of normal growth and development. The mean body length increased from $47 \%$ of controls in igf $1 \mathrm{r}$ MO-injected embryos to $80 \%$ in igf1r MOs \pm igf1r mRNAinjected embryos. Somite number also increased from $16.7 \pm 0.41$ in igf1r MO-injected embryos to $23.9 \pm 0.59$ in igf1r MOs \pm igf1r mRNA-injected embryos $(P<0.0001)$ (Figure $3 c$ and d). Additionally, embryos with reduced IGF1R signaling exhibited a significant decrease in $r \times 1$ expression in the retina, whereas embryos coinjected with igf1r MOs \pm igf1r mRNA exhibited a substantial recovery of $r \times 1$ expression (Figure 3b). Taken together, these data indicated that IGF1R signaling is required for proper zebrafish embryo growth and development but does not play an indispensable role in the patterning of brain or other embryonic tissues examined.

Inhibition of IGF1R signaling results in increased neuronal apoptosis. IGF1R signaling is a potent promoter of cell survival in a variety of cultured mammalian cells. ${ }^{19-21}$ To test whether loss of IGF1R signaling leads to increased apoptosis in a developing vertebrate embryo, we measured the activity of caspase 3 , an executioner caspase. Reducing IGF1R signaling resulted in a four-fold, highly significant increase in caspase 3 activities over controls and coinjection

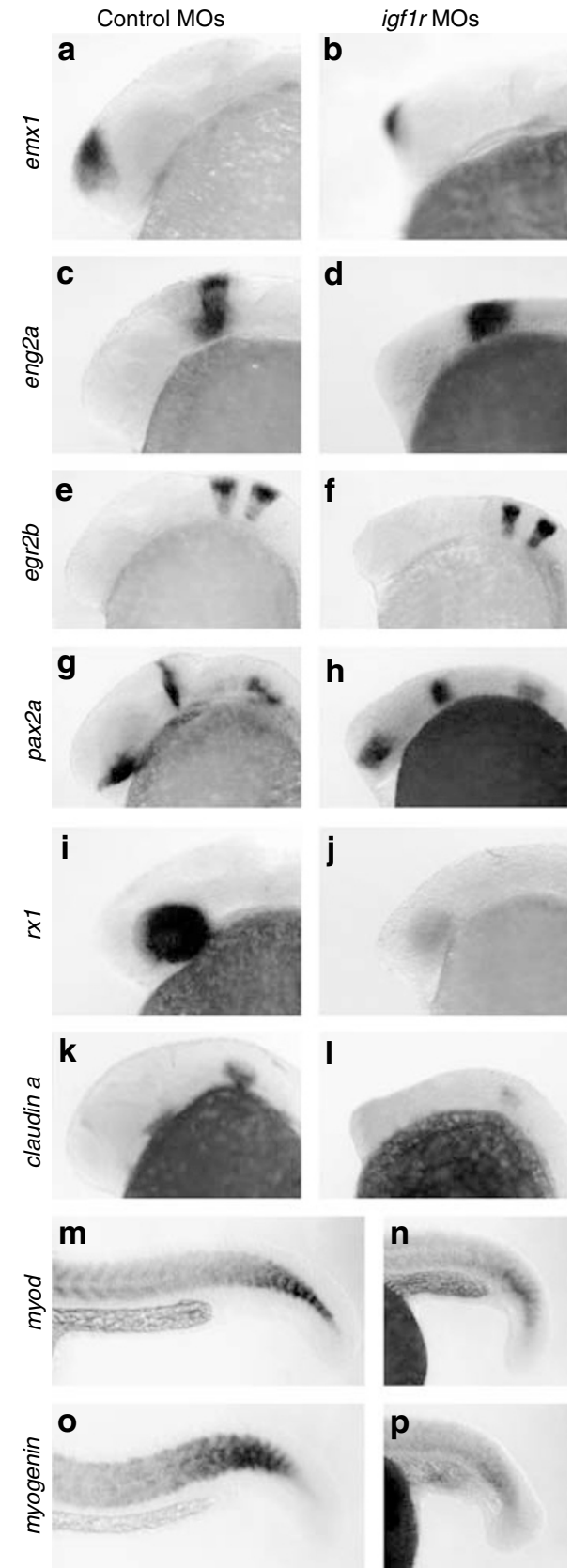

Figure 2 Inhibition of IGF1R signaling does not alter embryo patterning. (a-p) Whole mount in situ hybridization analysis of various marker genes in control (left panels) and igf1r MO-injected (right panels) embryos at $24 \mathrm{hpf:} \mathrm{emx1}$ expression in the forebrain $(\mathbf{a}, \mathbf{b})$; eng2a expression in the mid-hindbrain boundary $(\mathbf{c}, \mathbf{d})$; egr2b expression in the third and fifth rhombomeres of the hindbrain (e, f); pax2a expression in the optic stalk, mid-hindbrain boundary and hindbrain $(\mathbf{g}, \mathbf{h}) ; r \times 1$ expression in the retina $(\mathbf{i}, \mathbf{j})$; claudin a expression in the otic vesicle $(\mathbf{k}, \mathbf{l}) ; m y o D(\mathbf{m}$, $\mathbf{n})$ and myogenin $(\mathbf{o}, \mathbf{p})$ expression in the somatic myotome. Similar patterns were observed in all embryos examined in each group $(N=8-10)$

of the igf1r MOs along with igf1r mRNA reduced caspase 3 activities to the basal level (Figure 4a). We next performed TUNEL on cryosections of $20 \mathrm{hpf}$ control and igf1r MOinjected embryos to decipher patterns of apoptosis. Igf1r MOinjected embryos had significantly greater numbers of 
a

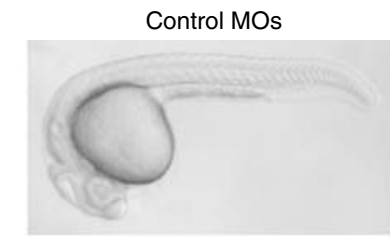

b

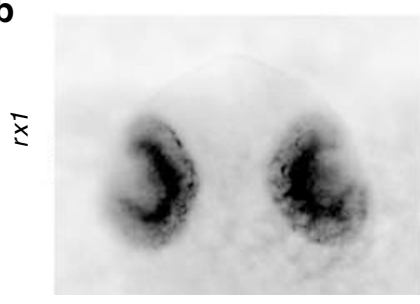

C

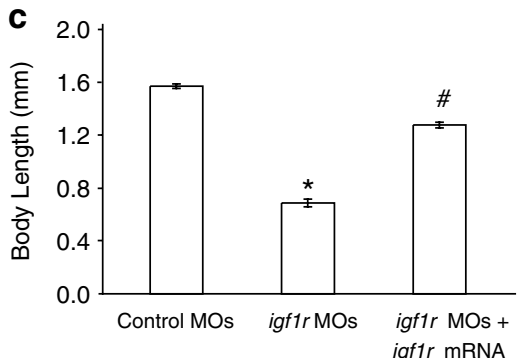

igf1r MOs
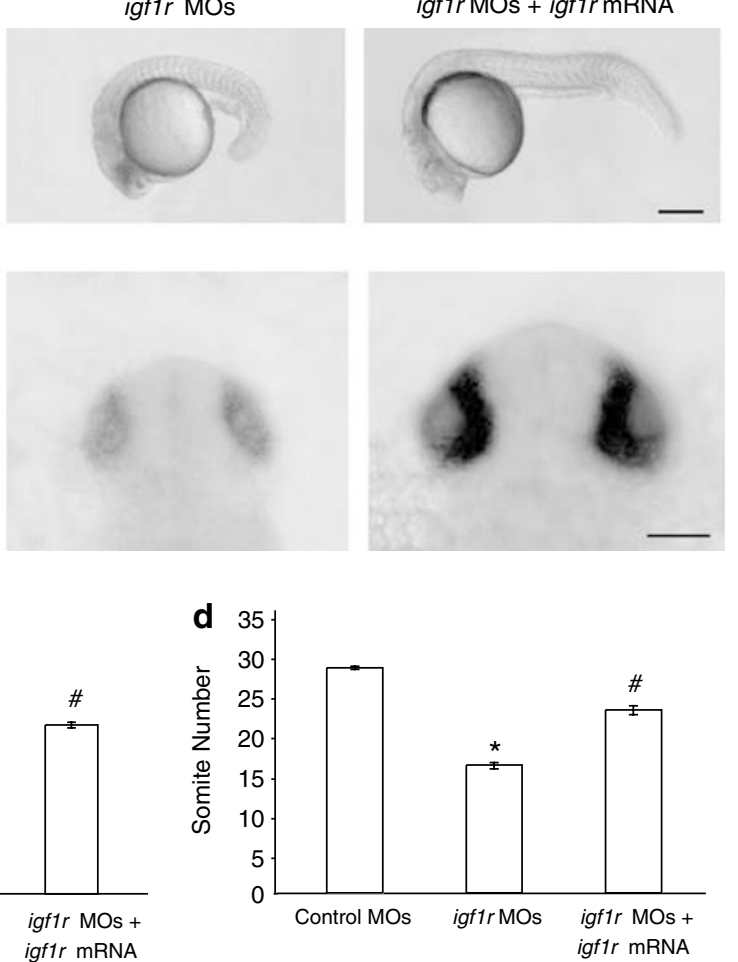

Figure 3 Coinjection of igf1rmRNA with igf1rMOs rescues the growth and developmental defects. (a) Phenotypes of embryos injected with control MOs, igf1rMOs or igf1r MOs \pm igf1r mRNA at $24 \mathrm{hpf}$. In three separate microinjection experiments, $70 \%$ of igf1r MOs \pm igf1r mRNA-injected embryos exhibited this phenotype $(N=252)$. Lateral views, anterior to the left, dorsal to the top. Scale bar $=250 \mu \mathrm{m}$. (b) Expression of $r \times 1 \mathrm{mRNA}$ in the retina of embryos injected with control MOs, igf1r MOs or igf1r MOs \pm igf1r mRNA at $24 \mathrm{hpf}$. Note the recovery of $r \times 1$ expression upon coinjection of igf1r MOs with igf1rmRNA. Dorsal views, anterior to the top. Scale bar $=100 \mu \mathrm{m}$. Similar patterns were observed in all embryos examined in each group $(N=12-14)$. (c, d) Body length and somite number in embryos in the above treatment groups at $24 \mathrm{hpf}$. Graphs represent mean values of a total of 45 embryos resulting from three independent microinjection experiments. ${ }^{*} P<0.0001$ between control and igf1r MO-injected embryos. \# $P<0.0001$ between igf1r MOs and igf1r MOs \pm igf1r mRNA-injected embryos

apoptotic cells throughout the brain region (Figure $4 b$ ). Concurrently, there was a substantial reduction in $r \times 1$ mRNA expression in retinal tissues in igf1r MO-injected embryos (Figure 4c). TUNEL analysis of the trunk regions of these embryos revealed a similar increase in apoptosis in igf1r MO-injected embryos. The majority of apoptotic cells were found in the spinal cord (Figure 4d). The elevated neuronal apoptosis was reduced by coinjection of the igf1r MOs with igf1r mRNA (data not shown). Analysis of caudal primary motoneuron (CaP) by SV2 immunostaining indicated a reduction in the number of $\mathrm{CaP}$ motoneurons in igf1r $\mathrm{MO}$ injected embryos (Figure 4e). These results strongly suggest that IGF1R signaling is an important survival signal for neuronal cells in developing zebrafish embryos.

To test whether this increased neuronal apoptosis was the cellular basis underlying the retina and $\mathrm{CaP}$ motoneuron defects in igf1r MO-injected embryos, zebrafish antiapoptotic bcl2-like ( $b c l 2 l)$ mRNA was coinjected with igf1rMOs to inhibit apoptosis. Injection of bcl2l mRNA caused a significant reduction of caspase 3 activity, greatly attenuated the increased apoptosis in the brain and spinal cord and resulted in a recovery of retina and $\mathrm{CaP}$ motoneurons (Figure $4 \mathrm{a}-\mathrm{e}$ ). These findings suggest that promotion of neuronal cell survival is a major mechanism by which IGF1R signaling regulates zebrafish retina and other neural tissue development.
Expression of a dominant-negative IGF1R phenocopies igf1r MO-injected embryos. The finding that IGF1Rdeficient embryos progressed normally through development until approximately $16 \mathrm{hpf}$ and then arrested at $18 \mathrm{hpf}$ is both intriguing and puzzling, because both IGF ligands and IGF1Rs are expressed in a widespread fashion throughout all stages of embryogenesis. ${ }^{14}$ Because it is known that maternal proteins can influence early development in zebrafish, ${ }^{22}$ we postulated that maternal IGF1R protein may keep normal development up to $16 \mathrm{hpf}$. To test this idea and to investigate the developmental roles of IGF1R signaling further using an independent approach, a zebrafish dominant-negative IGF1R was constructed by deleting the intracellular signaling domain of IGF1Ra and tagging its $\mathrm{C}$ terminus with EGFP (dnIGF1R:GFP) (Figure 5a). Successful expression of the dnIGF1R:GFP fusion protein was confirmed by Western immunoblot (IB) using a GFP antibody (Figure $5 \mathrm{~b}$ ) and by observing GFP fluorescence microscopically (data not shown). Subsequent biochemical analysis revealed that overexpression of the dnIGF1R:GFP fusion protein did not alter total IGF1R protein levels but significantly diminished the levels of phosphorylated and activated IGF1Rs (Figure 5c). Further analysis revealed a major decrease in the levels of phosphorylated Akt (Figure $5 d$ ), which is a major downstream effector of the IGF1R. ${ }^{4}$ 

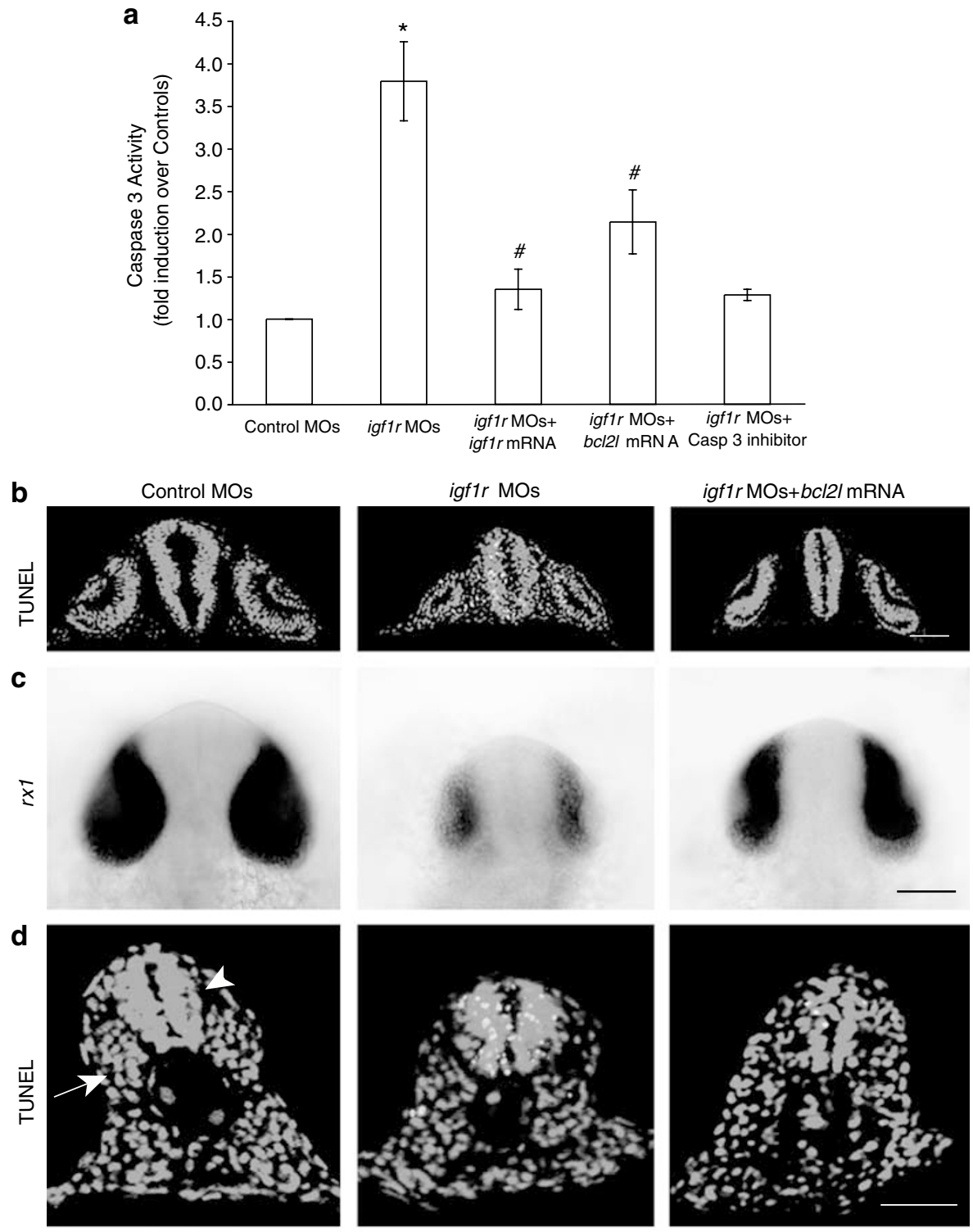

e
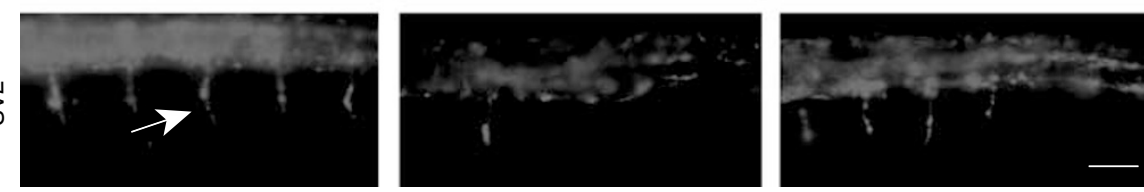

Figure 4 Inhibition of IGF1R signaling increases neuronal apoptosis. (a) Caspase 3 activity in embryos injected with control MOs, igf1r MOs, igf1r MOs \pm igf1r mRNA and igfirMOs $\pm b c / 2 / \mathrm{mRNA}$ at $24 \mathrm{hpf}$. The addition of a caspase 3 inhibitor, DEVD-fmk, to the lysates of igf1rMO-injected embryos was used as a control for specificity. The graph represents means from three independent microinjection experiments, each with 25 embryos per group. ${ }^{*} P<0.001$ for comparisons between control and igf1r MO-injected embryos. \#, $P<0.001$ for comparisons between igf1r MO-injected embryos with either igf1r MOs \pm igf1r mRNA, or igf1r MOs $\pm b c / 21 \mathrm{mRNA}$-injected embryos. (b) TUNEL (red) of cryosections of brain regions from $20 \mathrm{hpf}$ control MOs, igf1r MOs and igf1r MOs $\pm b c l 2 \mathrm{mRNA}$-injected embryos. Nuclei were counterstained with sytox (green). Crosssectional views, anterior to the top. Scale bar $=50 \mu \mathrm{m}$. (c) $R x 1 \mathrm{mRNA}$ expression in control MOs, igf1r MOs and igf1r MOs $\pm b c / 2 \mathrm{mRNA}$-injected embryos. Dorsal views, anterior to the top. Scale bar $=100 \mu \mathrm{m}$. (d) TUNEL (red) of cryosections of posterior trunk region of $20 \mathrm{hpf}$ control MOs, igf1r MOs and igf1r MOs $\pm b c / 2 \mathrm{mRNA}$-injected embryos. Nuclei were counterstained with sytox (green). The spinal cord (white arrowhead) and myotome (white arrow) are indicated in the control MO-injected embryo. Cross-sectional views, dorsal to the top. Scale bar $=20 \mu \mathrm{m}$. (e) SV2 labeling of CaP motoneurons in $20 \mathrm{hpf}$ control MOs (white arrow), igf1rMOs and igftrMOs $\pm b c l 2 \mathrm{mRNA}$ injected embryos. Lateral views, anterior to the left, dorsal to the top. Scale bar $=100 \mu \mathrm{m}$. Similar patterns were observed in all embryos examined $(N=12-15)$

Overexpression of the dnIGF1R:GFP fusion protein produced a growth-retarded and developmentally arrested embryo, similar to the phenotype of igf1r MO-injected embryos (Figure 5e). The mean somite number of dnIGF1R: GFP mRNA-injected embryos at $24 \mathrm{hpf}(17.51 \pm 1.24$ somites) was significantly lower compared to control GFP mRNAinjected embryos $(29.27 \pm 0.78 ; P<0.0001)$. TUNEL analysis revealed a similar pattern of apoptosis as in igf1r MO-injected embryos, predominately in the brain and spinal cord (data not shown). In addition, caspase 3 activation was also 
a

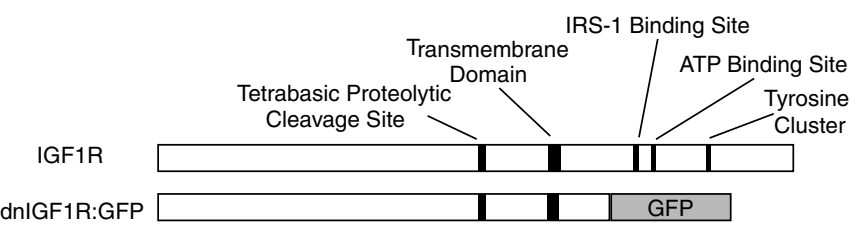

b
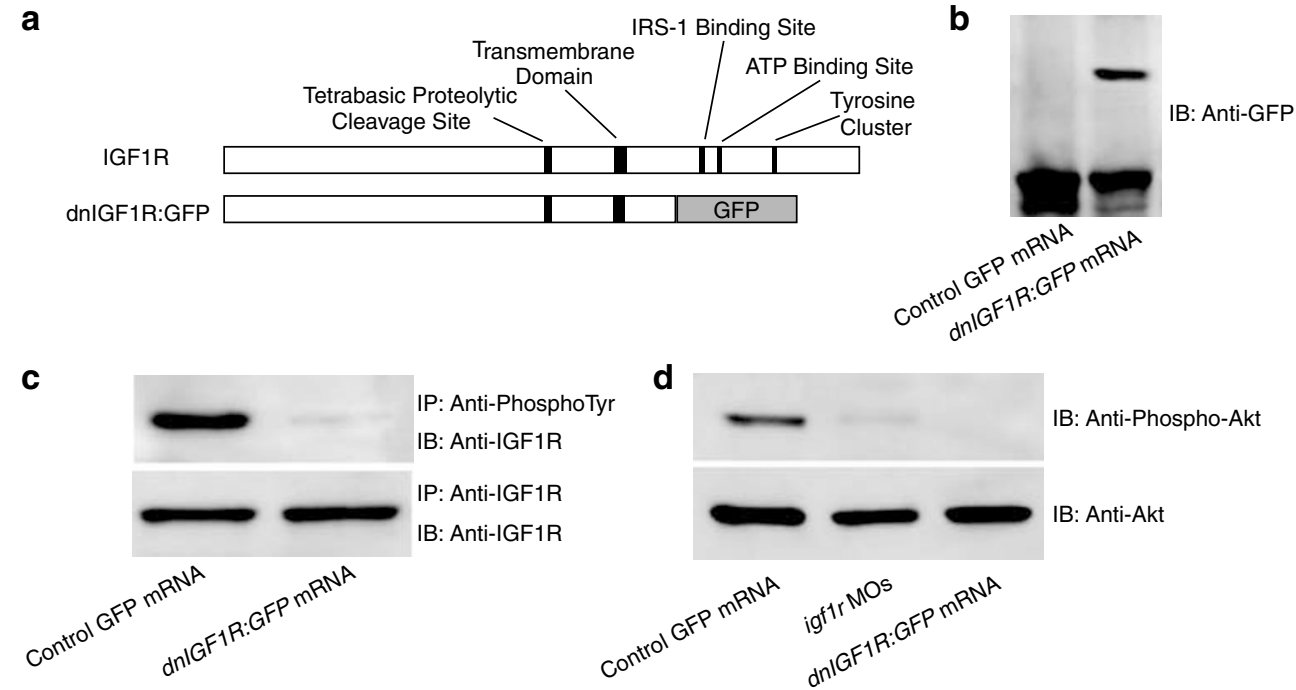

d

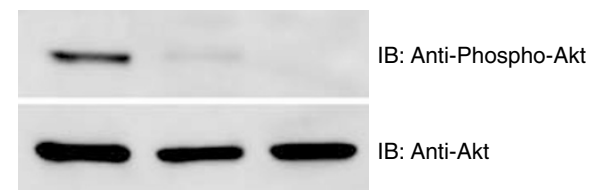

e

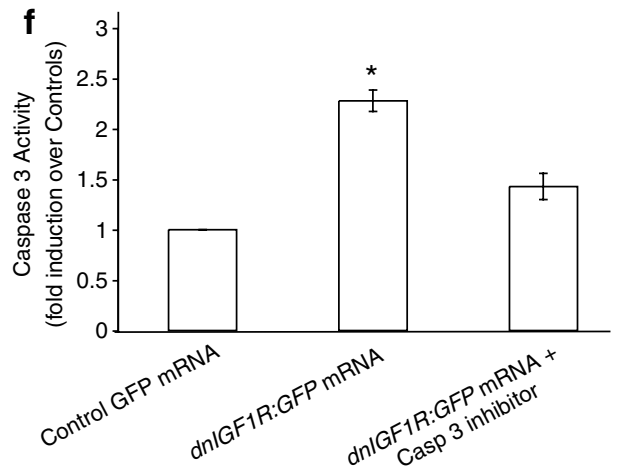

Figure 5 Inhibition of IGF1R signaling by a dominant-negative IGF1R:GFP fusion protein (dnIGF1R:GFP). (a) A schematic diagram of the dnIGF1R:GFP fusion protein, which possesses transmembrane and dimerization domains but lacks the intracellular domain necessary for autophosphorylation and intracellular signaling. (b) Lysates from control GFP mRNA and dnIGF1R:GFP mRNA-injected embryos at $20 \mathrm{hpf}$ were analyzed by IB using a GFP antibody. The dnIGF1R:GFP fusion protein was detected at the predicted $\sim 60 \mathrm{kDa}$ size, compared to the $\sim 28 \mathrm{kDa}$ band corresponding to GFP. (c) IP and IB analysis of $20 \mathrm{hpf}$ embryos injected with either control GFP mRNA or dnIGF1R:GFP mRNA using IGF1R and phosphotyrosine antibodies. Similar results were obtained in two other microinjection experiments. (d) IB analysis of $20 \mathrm{hpf}$ embryos injected with control GFP mRNA, dnIGF1R:GFP mRNA or igf1r MOs, using total and phospho-Akt antibodies. Similar results were obtained in two other microinjection experiments. (e) Phenotypes of control GFP mRNA and dnIGF1R:GFPmRNA-injected embryos at $24 \mathrm{hpf}$. In three separate microinjection experiments, $81 \%$ of dnIGF1R:GFP mRNA-injected embryos exhibited this phenotype $(N=183)$. (f) Caspase 3 activation in embryos injected with control GFP mRNA or dn/GF1R:GFP mRNA at $24 \mathrm{hpf}$. The graph represents mean values of three independent microinjection experiments, each with 25 embryos per group. The addition of a caspase 3 inhibitor, DEVD-fmk, to the lysates of $d n$ IGF1R:GFP mRNA-injected embryos was used as a control for specificity. ${ }^{*} P<0.0001$ for comparisons between control GFP mRNA and dnIGF1R:GFP mRNAinjected embryos

significantly increased compared to control GFP mRNAinjected embryos (Figure 5f). These results indicated that expression of the dnIGF1R:GFP fusion protein effectively inhibited IGF1R signaling, and provide further evidence supporting a critical role for IGF1R signaling in promoting neuronal cell survival, as well as proper embryonic growth and development. They also suggest that the late onset of IGF1R loss-of-function phenotypes is not likely because of maternal IGF1R protein.

Inhibition of IGF1R signaling does not alter early central nervous system patterning. Given recent reports for a role for IGF signaling in the induction of anterior neural tissue and patterning ${ }^{15-17}$, we tested whether igf1r MOs and dnIGF1R: GFP mRNA-injected embryos exhibited defects in patterning the central nervous system (CNS). Neither igf1r MOs nor
dnIGF1R:GFP mRNA-injected embryos exhibited defects in CNS patterning, as indicated by the expression of otx2 (presumptive forebrain and midbrain), pax6b (eye field and forebrain) and shh (notochord) at $10 \mathrm{hpf}$. As shown in Figure 6a, the expression patterns of these genes, which are all critical for normal neural development, are indistinguishable among controls, igf1r MOs and dnIGF1R: GFP mRNA-injected embryos. We next performed flow cytometry analysis at $10 \mathrm{hpf}$. Representative cell cycle histograms are shown in Figure 6b, and there are no major differences among the treatment groups in terms of the percentages of cells in each cell cycle phase (Figure 6b), although both igf1r MOs and dnIGF1R:GFP mRNA-injected embryos exhibited a modest but statistically significant increase in the percentages of cells in the $G_{1}$ phase 
a
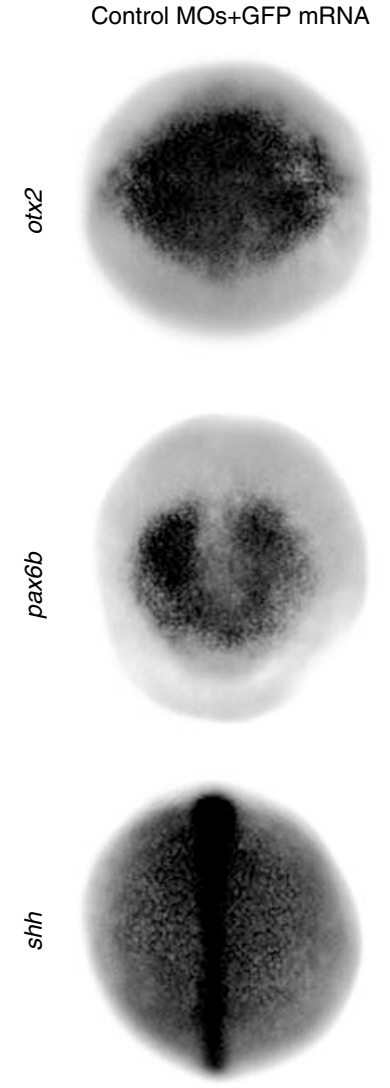

igf1r MOs
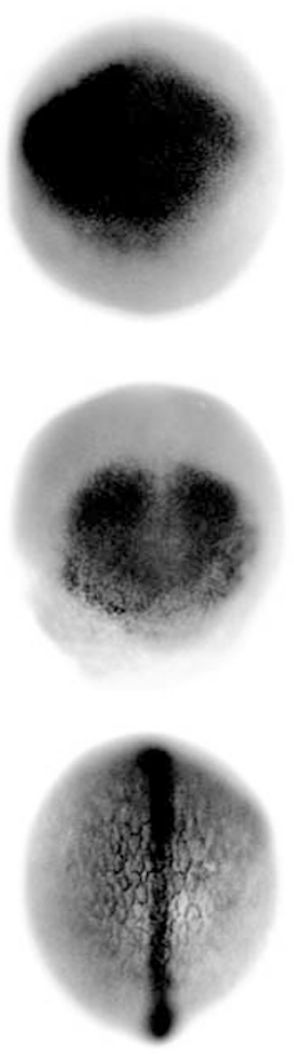

dnIGF1R:GFP mRNA
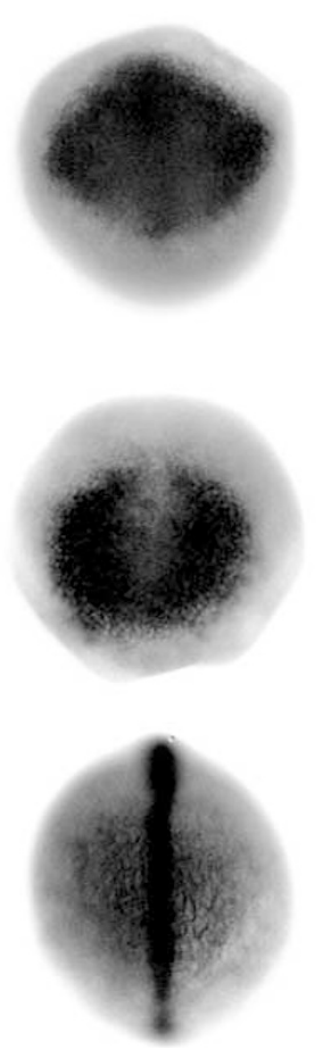

dnIGF1R:GFP mRNA

b

Control MOs+GFP mRNA
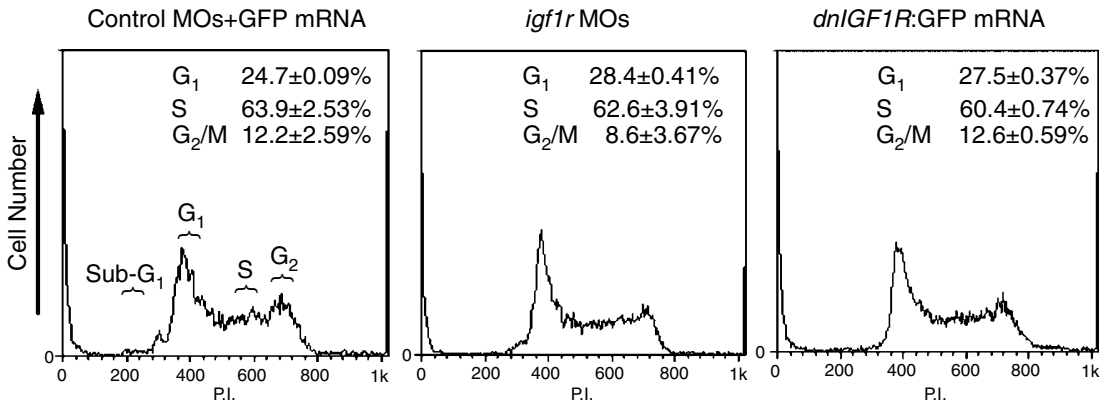

Figure 6 Inhibition of IGF1R signaling does not alter CNS patterning. (a) Expression of otx2 (presumptive forebrain and midbrain), pax6b (eye field and forebrain) and shh (notochord) is indistinguishable among controls, igf1r MO-injected embryos, and dnIGF1R:GFP mRNA-injected embryos at 10 hpf. Similar patterns were observed in all embryos examined in each group $(N=12-15)$. (b) Representative cell cycle histograms of control, igf1r MO-injected and dnIGF1R:GFP mRNA-injected embryos at $10 \mathrm{hpf}$. The mean percentages of cells in each phase of the cell cycle for three separate microinjection experiments are given (upper right of each histogram)

compared to controls. igf1r MOs and dnIGF1R:GFP mRNAinjected embryos were not significantly different from each other. Additionally, there were no significant sub-G1 peaks in control or IGF1R loss-of-function embryos, indicating low levels of apoptosis among all groups at this stage (Figure 6b).

Inhibition of IGF1R signaling affects cell cycle progression. Although overexpression of bcl2l in igf1r $\mathrm{MO}$-injected embryos reduced apoptosis and rescued the retinal and motoneuron defects, it had no effect on the developmental arrest. As shown in Figure 7a, $24 \mathrm{hpf} i g f 1 r$ MOs $\pm b c / 2 /$ mRNA-injected embryos did not advance further than $18 \mathrm{hpf}(18.13+0.98$ somites). We, therefore, tested whether the developmental arrest observed in igf1r MOinjected embryos was because of defects in cell proliferation. Indeed, igf1r MOs and igf1r MOs $\pm b c / 2$ I mRNA-injected embryos exhibited significantly less BrdU-positive cells compared to controls (61 and $50 \%$ of the control group, respectively) (Figure $7 \mathrm{~b}$ ). To examine this cell proliferation defect in more detail, flow cytometry analysis was performed. Representative cell cycle histograms of $20 \mathrm{hpf}$ embryos injected with control MOs, igf1r MOs, igf1r MOs \pm bcl2l mRNA, or igf1r MOs \pm igf1r mRNA are shown in Figure 7c. There is a clear increase in the amount of sub- $\mathrm{G}_{1}$ cells in igf1r MO-injected embryos. Coinjection of bcl2l mRNA or 
a

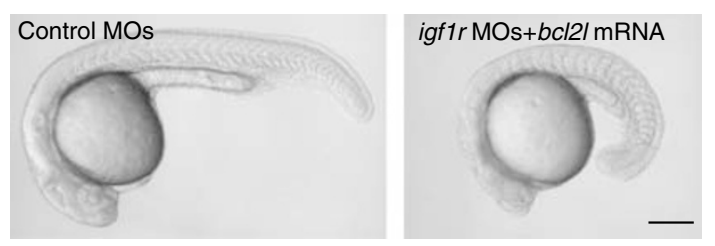

b

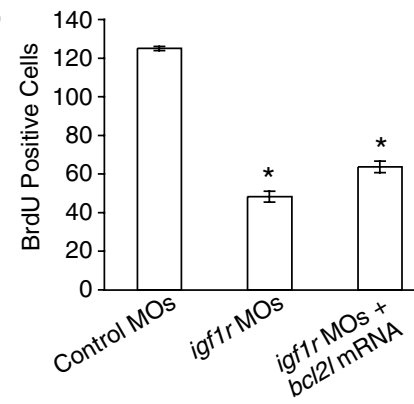

C

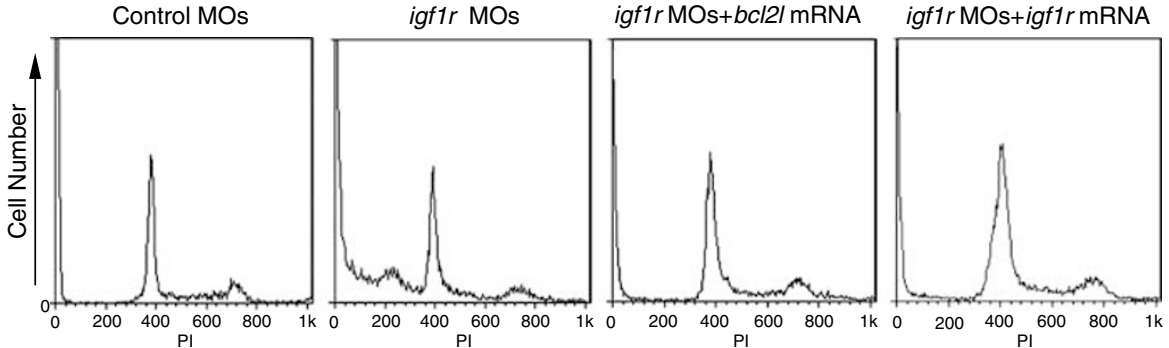

d

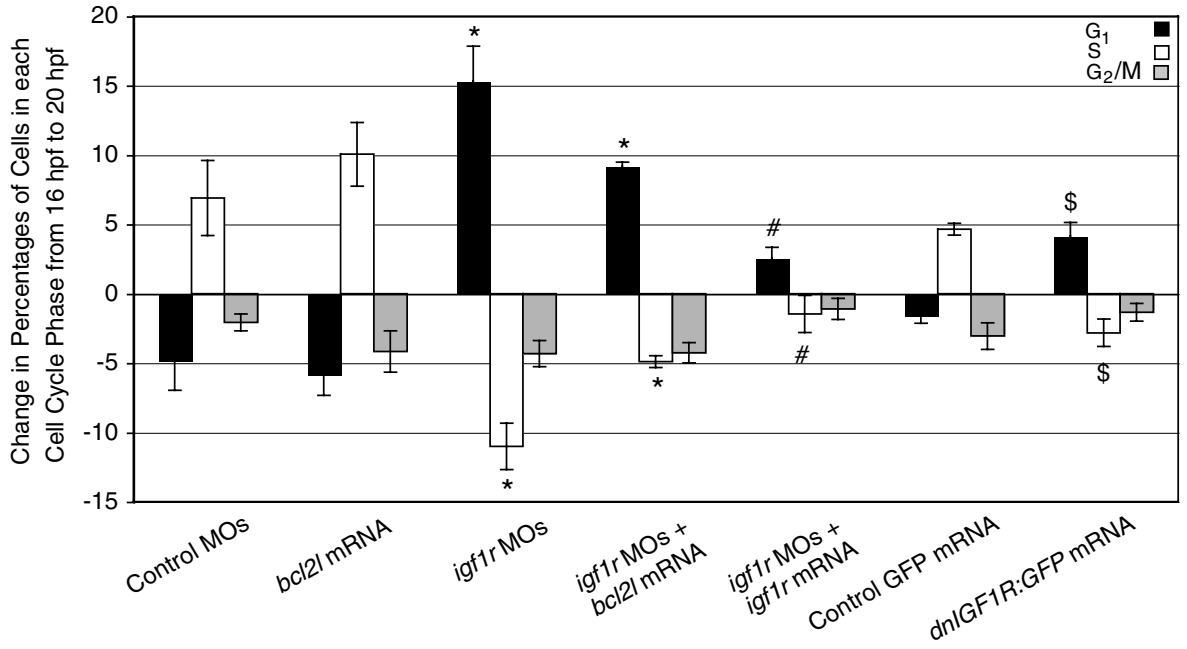

Figure 7 Inhibition of IGF1R signaling causes cell cycle defects. (a) Phenotypes of embryos injected with either control MOs or igf1rMOs $\pm b c / 2 / \mathrm{mRNA}$ at $24 \mathrm{hpf}$. In three separate microinjection experiments, $73 \%$ of igf1r MOs $\pm b c / 2$ I mRNA-injected embryos exhibited this phenotype $(N=176)$. Scale bar $=250 \mu \mathrm{m}$. (b) Quantification of BrdU positive cells in $20 \mathrm{hpf}$ embryos injected with control MOs, igf1r MOs or igf1r MOs $\pm b c / 2 / \mathrm{mRNA}$. Graph represents mean values of six embryos (from two independent microinjection experiments, each with 3 embryos per treatment group). ${ }^{\star} P<0.0001$ between control and igf1r MO-injected embryos, and between control and igf1r MOs $\pm b c l 21$ mRNA-injected embryos. (c) Representative cell cycle histograms of 20 hpf embryos injected with control MOs, igf1r MOs, igf1r MOs $\pm b c / 2 /$ mRNA or igf1r $\mathrm{MOs} \pm$ igf1rmRNA. Note the reduction of the sub-G $\mathrm{G}_{1}$ peak in igf1rMO-injected embryos upon coinjection of either bcl2/mRNA or igf1rmRNA. (d) Changes in the percentages of cells in each cell cycle phase from $16 \mathrm{hpf}$ to $20 \mathrm{hpf}$. Graph represents mean values of three independent microinjection experiments. ${ }^{*}, P<0.0001$ for comparing the percentages of cells in the $\mathrm{G}_{1}$ or $\mathrm{S}$ phase between control $\mathrm{MO}$ and igf1r MO-injected embryos, with or without coinjection of $b c / 2 / \mathrm{mRNA}$. \#, $P<0.0002$ for comparing the percentages of cells in the $G_{1}$ or $S$ phase between igf1rMOs and igf1rMOs \pm igf1rmRNA-injected embryos. $\$, P<0.005$ for comparing the percentages of cells in the $G_{1}$ or $S$ phase between control GFP mRNA and dnIGF1R:GFP mRNA-injected embryos

igf1r mRNA reduced it to control levels (Figure 7c), suggesting apoptotic inhibition.

When the change in the percentages of cells in each cell cycle phase, from $16 \mathrm{hpf}$ (the onset of developmental arrest) to $20 \mathrm{hpf}$ ( $2 \mathrm{~h}$ after developmental arrest), was quantified and compared, we found no significant differences in the cell cycle profiles between control $\mathrm{MO}$ and $b c / 2 / \mathrm{mRNA}$-injected groups (Figure 7d). Both exhibited a decrease in the percentage of $\mathrm{G}_{1}$-phase cells and an increase in the percentage of S-phase cells from 16 to $20 \mathrm{hpf}$. In contrast, igf1r MO-injected embryos exhibited a significant increase in the percentage of $\mathrm{G}_{1}$-phase cells and a decrease in the percentage of S-phase cells from 16 to 20 hpf (Figure $7 d$ ). This significant increase in $\mathrm{G}_{1}$-phase cells and decrease in S-phase cells suggests a defect in cell cycle progression at the $\mathrm{G}_{1}$ to $\mathrm{S}$ transition in these igf1r $\mathrm{MO}$ injected embryos and correlates well with the onset of developmental arrest. Apoptotic inhibition by coinjection of bcl2/ mRNA did not alter these patterns (Figure 7d). Coinjection of igf $1 \mathrm{r}$ mRNA partially, but significantly, restored normal cell cycle progression by decreasing the percentage of $\mathrm{G}_{1}$-phase cells and increasing the percentage of $\mathrm{S}$-phase cells (Figure 7d). Embryos injected with dnIGF1F:GFP mRNA 
exhibited a significant increase in the percentage of $G_{1}$-phase cells and a significant decrease in the percentage of S-phase cells from $16 \mathrm{hpf}$ to $20 \mathrm{hpf}$, compared to control GFP mRNAinjected embryos (Figure 7d). Together, these data suggested that the developmental arrest resulting from the inhibition of IGF1R signaling is independent of apoptosis but is correlated with a defect in the ability of embryonic cells to progress through the cell cycle.

\section{Discussion}

Our loss-of-function study demonstrated that Igf1r-mediated signaling is required for the proper growth, development and survival of zebrafish embryos. Knockdown of the igf1r genes or specific inhibition of Igf1r-mediated signaling results in increased embryonic lethality. Igf1r-deficient embryos are significantly smaller in body length and they did not advance beyond a developmental stage equivalent to approximately $18 \mathrm{hpf}$ in wild-type zebrafish but exhibited no patterning defects. These phenotypes are consistent with those reported in mutant mice i1,12,23 and Drosophila ${ }^{24}$ but differ from previous studies in Xenopus. ${ }^{15,16}$

Although IGF signaling was proposed to be an anteriorizing or neural induction signal in Xenopus, ${ }^{15,16}$ our results show that reduction of Igf signaling not only affects retina, but also other tissues throughout the zebrafish embryo. This is most evident in disrupted $\mathrm{CaP}$ motoneuron survival and increased apoptosis in the spinal cord. Depletion of Igf1r-mediated signaling also significantly delays heart morphogenesis and somitogenesis. These results indicate that Igf signaling exerts actions on most, if not all, embryonic tissues, and therefore does not function specifically as an anteriorizing signal in zebrafish. This conclusion is in good agreement with the widespread expression patterns of the lgf ligands and receptors in zebrafish embryos. ${ }^{14}$ Differences in anterior neural induction between Xenopus and other vertebrates have been documented previously. For example, inhibiting BMP signaling by overexpressing follistatin, Noggin, or Chordin, anteriorizes Xenopus embryos; ${ }^{25}$ however, BMP inhibition is not sufficient to induce a neural cell fate in chick or mouse embryos. ${ }^{26}$ Similarly, overexpression of cerberus induces head formation in Xenopus embryos, but head formation is normal in mice null for Cer1 ${ }^{27}$ There are also notable differences in the methodologies between our study and previous studies in Xenopus and zebrafish. In the current study, we employed two independent approaches to inhibit IGF1R signaling: multiple gene-specific MOs targeting both igf1r genes and a dominant-negative IGF1R fusion protein possessing the transmembrane domain. Both methods were shown to reduce IGF1R signaling in vivo effectively and they yielded similar phenotypes. The study by Richard-Parpaillon et al. $^{16}$ used only one igf1r MO targeting one Xenopus igf1r gene. Pera et al. ${ }^{15}$ and Eivers et al. ${ }^{17}$ overexpressed a secreted form of a truncated IGF1R lacking both the transmembrane and intracellular domains. The lack of a transmembrane anchor may affect its effectiveness as a dominant-negative inhibitor because there are a family of secreted IGF-binding proteins (insulin-like growth factor binding proteins), which bind IGFs with equal or even greater affinity than the IGF1R. ${ }^{3,28-30}$ IGFBPs are present at high levels in specific embryonic tissues and could potentially outcompete a dominant-negative IGF1R that does not contain an appropriate membrane anchor, thereby reducing the knockdown efficacy in those tissues.

The easily accessible and transparent zebrafish embryo and the functional conservation of the IGF signaling system have provided an excellent opportunity for an in-depth investigation into the cellular basis of IGF signaling during early embryogenesis. Taking advantage of this model organism, we showed that knockdown or inhibition of the zebrafish IGF1R signaling significantly increased caspase 3 activity and TUNEL-positive cells. In the brains of IGF1Rdeficient embryos, we observed a widespread pattern of apoptosis. In the trunk, apoptotic cells were concentrated in the spinal cord. Consistent with this increase in neuronal apoptosis, IGF1R-deficient embryos had a disproportionate reduction in retinal tissue compared to other anterior tissue and disruptions in $\mathrm{CaP}$ motoneuron formation/survival. Overexpression of bcl2l in IGF1R-deficient embryos led to a recovery of these tissues, strongly suggesting that IGF1R signaling regulates the development of the retina and $\mathrm{CaP}$ motoneurons, and possibly other neuronal tissues, by promoting cell survival.

It is interesting that embryos with reduced IGF1R signaling progressed normally until approximately $16 \mathrm{hpf}$ and became arrested at $\sim 18 \mathrm{hpf}$. Reduced somite number and retarded heart morphogenesis was manifestations of this developmental arrest. In agreement with our findings in zebrafish, igf1r null mutant mice exhibit no significant differences in growth rate compared to wild-type littermates until embryonic day 11.0. ${ }^{11,12}$ Whether elevated apoptosis played any role in these defects in developmental timing was not investigated. In this study, we found that overexpression of bc/2/ could not restore normal developmental timing, suggesting that elevated apoptosis is unlikely the cellular basis underlying the developmental arrest. We noted that embryos with reduced IGF1R signaling exhibited a significant decrease in the number of proliferative cells, supporting the notion that endogenous IGF signaling may be required for embryonic cell cycle progression. Indeed, we found a significant increase in the percentage of $G_{1}$-phase cells and a significant decrease in the percentage of S-phase cells in embryos deficient in IGF1R signaling compared to controls. This phenotype was unaffected by apoptotic inhibition but could be rescued by coinjection of igf1r mRNA. These data indicate a strong correlation between the developmental arrest phenotype and defects in cell cycle progression at the $G_{1}$ to $S$ transition. This conclusion is consistent with a recent study in mouse suggesting a role for IGF1 in accelerating the cell cycle by decreasing the $\mathrm{G} 1$ phase and increasing cell cycle reentry in the embryonic cerebral cortex. ${ }^{31}$ Moreover, several studies in Drosophila point to a critical role for insulin receptor/IGF1R signaling in controlling the duration of embryonic development, total body size and organ size by regulating the rates of cell growth and proliferation. ${ }^{32,33}$

We and others have previously shown that the zebrafish IGF ligands and IGF1Rs are highly expressed in almost all tissues and at all stages of embryogenesis. ${ }^{14,17}$ In fact, IGF, IGF1R and IGFBP transcripts are detected even at the onecell stage. ${ }^{3,14}$ It is, therefore, intriguing that the developmental 
arrest phenotype in IGF1R-deficient embryos did not occur until approximately $16 \mathrm{hpf}$. The reason for this is yet unclear; however, it cannot be attributed to maternal IGF1R protein, because igf1r MOs and dnIGF1R:GFP mRNA-injected embryos exhibited nearly identical developmental arrest phenotypes. Future studies are needed to determine whether other components of the IGF signaling cascade, downstream of the IGF1R, are involved in the interesting developmental regulation of IGF1R signaling during zebrafish embryogenesis.

\section{Materials and Methods \\ Animals and reagents. Adult wild-type zebrafish (Danio rerio) were maintained at $28^{\circ} \mathrm{C}$ on a $14 \mathrm{~h}: 10 \mathrm{~h}$ (light:dark) cycle and fed twice daily. Embryos were generated from natural crosses. Fertilized eggs were raised in embryo medium at $28.5^{\circ} \mathrm{C}$ and staged by hours postfertilization or standard criteria. ${ }^{34}$ All experiments were conducted in accordance with guidelines approved by the University Committee on the Use and Care of Animals, University of Michigan. \\ All chemicals and reagents were purchased from Fisher Scientific (Pittsburgh, PA, USA) unless otherwise noted. RNase-free DNase was purchased from Promega (Madison, WI, USA). Restriction endonucleases were purchased from New England BioLabs (Beverly, MA, USA). Oligonucleotide primers for PCR were purchased from Invitrogen Life Technologies, Inc. (Carlsbad, CA, USA). The polyclonal IGF1R antibody (C-20) was purchased from Santa Cruz Biotechnology (Santa Cruz, CA, USA); the anti-phosphotyrosine antibody (PY20) from BD Biosciences (Franklin Lakes, NJ, USA) and the Tubulin antibody from Sigma. The SV2 monoclonal antibody was purchased from the Developmental Studies Hybridoma Bank (University of lowa). The anti-Akt and anti-Phospho-Akt antibodies (Ser473) were purchased from Cell Signaling (Danvers, MA, USA) and the anti-GFP antibody was purchased from Torrey Pines Biolabs (Houston, TX, USA). Dr. F Stockdale from Stanford University generously provided the F59 antibody.}

Morpholino knockdown. Gene-specific morpholino-modified oligonucleotides (MO) were purchased from Gene Tools, LLC (Philomath, OR, USA). Stock MO solutions were diluted in Danieau buffer and injected into fertilized embryos ( $1 \mathrm{nl} / \mathrm{embryo})$ at the one- or two-cell stage, as previously described. ${ }^{13}$ To ensure efficient knockdown of the igf1r genes, two nonoverlapping MOs were designed to target the translational start site and a region slightly upstream of that in the $5^{\prime}$ UTR of each igf1r subtype; the specificity and efficacy of each of these $\mathrm{MO}$ sequences have been confirmed using multiple approaches. ${ }^{13}$

Cloning and capped mRNA synthesis. CDNAs encoding full-length igf1ra and igf1rb were amplified by RT-PCR using Pfu DNA Polymerase (Stratagene, La Jolla, CA, USA) along with the following primers: igfira $5^{\prime}$ TTGGTACCGACCATGGGATCTGGAACAGCGAGG-3' and 5'-ACGACCATGTAG ACAAAGGGA-3', and igf1rb 5'-TTGGTACCGACCATGGGGTCTAGCAAACAGA GG-3' and $5^{\prime}$-GTCTCGAGCAGCAAGCCGAAGACTGG-3'. The resulted cDNAs were then cloned into the pBluescript II SK + vector. To generate a dominantnegative igf1ra construct, a DNA fragment was amplified by RT-PCR using the following primers: $5^{\prime}$-TTGGTACCGACCATGGGATCTGGAACAGCGAGG- $3^{\prime}$ and $5^{\prime}$-GTGGGCCCGCACAATGATGACAGCTACGAT-3'. This DNA fragment encodes a truncated IGF1Ra protein (from amino acids 1-974), containing the transmembrane and dimerization domains but lacks the tyrosine cluster, ATP binding site and the IRS-1 binding site. The same truncation in the human IGF1R has been shown to have the ability to form heterotetramers and the inability to activate intracellular signal transduction. ${ }^{35}$ The amplified igf1ra PCR product was digested with Apal and Kpnl and subcloned it into the pHsp70-GFP vector ${ }^{36}$, thus creating a dominant-negative IGF1Ra:GFP fusion protein (dnIGF1R:GFP). This construct was then subcloned into pBluescript II SK + using Kpnl and Xhol restriction sites, containing a previously inserted BGH polyA signal. A CDNA encoding the full-length zebrafish Bcl2-like (formerly known as BCL-xl) protein was cloned by RT-PCR based on sequences obtained from EST searches. The sequence is identical to a published cDNA sequence with the exception of one nucleotide in the $3^{\prime}$-UTR region. ${ }^{37}$ The above constructs were linearized with Notl digests, and capped mRNAs encoding these proteins were synthesized using T7 polymerase, as previously reported. ${ }^{38}$
Microinjection. MO, plasmid DNA or mRNA solutions were injected into 1-2 cell embryos as reported previously. ${ }^{38}$ To knockdown igftrexpression, we injected a mixture of all four MOs in the experiments described here. Each MO was injected at a final concentration of $1.25 \mathrm{ng} / \mathrm{embryo}$, for a total of $5 \mathrm{ng} \mathrm{MO} / \mathrm{embryo}$. Two genespecific missense control MOs were combined and injected at a final concentration of $2.5 \mathrm{ng} / \mathrm{embryo}$ for a total of $5 \mathrm{ng} \mathrm{MO} / \mathrm{embryo}$. For rescue experiments, igf1 ra and igf1rb mRNA were coinjected (100 pg/embryo each) with igf1ra MO2 and igf1rb MO2 at $2.5 \mathrm{ng} / \mathrm{embryo}$ each. These mRNAs lack the $5^{\prime} U T R$ and are resistant to the igf1r MOs targeting the $5^{\prime}$-UTR. The dn/GF1Ra:GFP mRNA was injected at a concentration of $750 \mathrm{pg} /$ embryo. The bcl2-like mRNA was injected at a concentration of $200 \mathrm{pg} / \mathrm{embryo}$. As a control for the dn/GF1Ra:GFP mRNA, we injected mRNA encoding GFP at a concentration of $750 \mathrm{pg} / \mathrm{embryo}$.

Body size and somite measurements. Embryo body length was quantified by measuring the linear distance from the mid-hindbrain boundary to the tail, with a line parallel to the top (dorsal) and bottom (ventral) of the image. Each line was then measured using a scale taken at the same magnification. Somite number was quantified by counting total somite number per embryo.

Immunoprecipitation and Western blot analysis. About 20 embryos for each group were dechorionated, deyolked and homogenized in $200 \mu \mathrm{l}$ of RIPA buffer (50 mM Tris- $\mathrm{HCl}, 150 \mathrm{mM} \mathrm{NaCl}, 2 \mathrm{mM}$ EGTA, 0.1\% Triton X-100, pH 7.5), containing $10 \mu \mathrm{g} / \mathrm{ml}$ aprotinin, $10 \mu \mathrm{g} / \mathrm{ml}$ leupeptin, $10 \mu \mathrm{g} / \mathrm{ml}$ pepstatin, $100 \mathrm{mM}$ PMSF and $0.1 \mathrm{M}$ sodium orthovanadate. The homogenates were briefly centrifuged to pellet cellular debris. Protein levels of each sample were quantified using a protein assay kit (Pierce Biotechnology Inc., Rockford, IL, USA). Equal amounts of protein were subjected to immunoprecipitation (IP) using either the phosphotyrosine antibody or the IGF1R antibody, or to Western blot analysis. For IP analysis, lysates were precleared using $15 \mu \mathrm{l}$ Protein G Agarose beads (50\% slurry) (Upstate Cell Signaling Solutions, Chicago, IL, USA). After the precleared lysate was transferred to a new tube, $5 \mu \mathrm{g}$ antibody was added and rotated at $4{ }^{\circ} \mathrm{C}$ for $2 \mathrm{~h}$. Protein $\mathrm{G}$ Agarose beads $(30 \mu l)$ were then added to the samples and rotated for another $2 \mathrm{~h}$ at $4{ }^{\circ} \mathrm{C}$, after which they were briefly centrifuged to pellet the beads. The supernatant was removed and stored for Western blot analysis. The beads were washed once with $1 \times$ PBS, pelleted and then the supernatant was discarded. The beads were boiled for $5 \mathrm{~min}$ in protein sample buffer $(250 \mathrm{mM}$ Tris-HCl, pH $6.8,5 \% \mathrm{SDS}, 0.25 \%$ bromophenol blue, $25 \%$ glycerol) under reducing conditions. The beads were pelleted again and the supernatant was subjected to Western blot analysis, which was performed as described previously. ${ }^{38}$ The anti-phosphotyrosine, Tubulin and GFP antibodies were used at 1:1000 dilution, and the anti-Phospho-Akt, total Akt and IGF1R antibodies were used at 1:500 dilution.

Whole mount in situ hybridization and immunocytochemistry. Whole mount in situ hybridization using digoxigenin (DIG)-labeled RNA riboprobes and whole mount immunocytochemistry was carried out as reported previously. ${ }^{14}$ For immunocytochemistry, heart ventricle tissue was labeled with a $1: 10$ dilution of F59, and motoneuron axons were detected with a 1:2000 dilution of anti-SV2. A $1: 100$ dilution of a Cy3-conjugated secondary antibody (Jackson ImmunoResearch Laboratories, West Grove, PA, USA) was used to detect primary antibodies. Images were viewed using a Nikon DC50NN camera mounted to a Nikon Eclipse E600 microscope.

Apoptosis assays. Embryo embedding, freezing and sectioning protocols were performed according to $\mathrm{Hu}$ et al. ${ }^{39}$. Sections $(10 \mu \mathrm{m})$ were collected and airdried at room temperature for $2 \mathrm{~h}$ before staining or storage at $-20^{\circ} \mathrm{C}$. For TUNEL assays, sections were stained using the In Situ Cell Death Detection Kit, TMR Red, according to the manufacturer's instructions (Roche, Nutlet, NJ, USA). Nuclei were counterstained with $50 \mathrm{nM}$ sytox (Molecular Probes, Carlsbad, CA, USA). Images were captured using a Nikon DC50NN camera mounted to a Nikon Eclipse E600 microscope. Images of TUNEL and sytox staining were captured separately and then merged using Adobe Photoshop. Whole mount TUNEL staining was also performed according to the manufacturer's instructions, and images were also captured using a Nikon DC50NN camera mounted to a Nikon Eclipse E600 microscope.

Caspase 3 activity was measured using the ApoAlert caspase 3 Activation Assay Kit (BD Biosciences, Franklin Lakes, NJ, USA) according to the manufacturer's instructions. Final values are expressed as fold induction of caspase 3 activity over controls (control MO-injected embryos or control GFP mRNA-injected embryos). 
BrdU analysis. Whole mount BrdU analysis of proliferative cells was done according to Gray et al. ${ }^{40}$ Briefly, embryos were soaked in BrdU solution for $20 \mathrm{~min}$ transferred to water lacking BrdU for $30 \mathrm{~min}$, then fixed and stained with a 1:100 dilution of a BrdU antibody (Invitrogen, Carlsbad, CA, USA). A 1:500 dilution of a Cy3-conjugated secondary antibody (Jackson ImmunoResearch Laboratories, West Grove, PA, USA) was used to detect the primary antibodies. Embryos were analyzed and images were captured using laser scanning confocal microscopy (Model LSM 510, Carl Zeiss, Thornwood, NJ, USA). Thirty-five serial sections $(5 \mu \mathrm{m})$ were taken off the brain of each embryo, including the area from the midhindbrain boundary forward to the forebrain. Fluorescent cells were counted in each section and care was taken to count each BrdU-positive cell only once, despite appearing in multiple sections.

Flow cytometry analysis. Cell cycle analysis was carried out using a FACSCalibur flow cytometer (BD Biosciences, Franklin Lakes, NJ, USA). Briefly, 40 deyolked embryos were homogenized in $1.5 \mathrm{ml}$ of DMEM $+10 \%$ fetal calf serum (FCS). Single-cell suspensions were obtained by sequentially straining the homogenates through $105 \mu \mathrm{m}$ and $40 \mu \mathrm{m}$ mesh filters. The cells were then washed and fixed in ethanol. After fixation, a propidium iodide $(\mathrm{PI})$ staining solution ( $50 \mu \mathrm{g} / \mathrm{ml} \mathrm{PI}, 100 \mu \mathrm{g} / \mathrm{ml}$ RNAse Type I, $0.1 \%$ sodium citrate, $0.0002 \%$ Triton X-100) was added, and the cells were incubated for $1 \mathrm{~h}$ in the dark at $4^{\circ} \mathrm{C}$. Samples were then subjected to flow cytometric analysis, using CellQuest Pro software (BD Biosciences, Franklin Lakes, NJ, USA). A two-parameter dot-plot of forward light scatter versus side scatter was constructed along with a two-parameter dot-plot of FL2 (PI) area versus width. In addition, a single-parameter PI (area) histogram was constructed to illustrate relative DNA content in each cell cycle phase. Cell cycle analysis (percentages of cells in each cell cycle phase) based on PI incorporation was done using Modfit LT (Verity Software House). Coefficients of variation were less than $5 \%$ in all experimental groups.

Statistics. Quantitative data are presented as means \pm standard error (S.E.M.). Differences among groups were statistically compared using one-way ANOVA followed with Fisher's post hoc tests. Differences between groups were statistically compared using unpaired $t$-tests.

Acknowledgements. We thank Drs. D Goldman, M Ekker, F Stockdale, R Kollmar, S Lyons, P Raymond and SJ Du for kindly providing reagents for this work. This study was supported by NSF IBN 0110864 to CD.

1. LeRoith D. Insulin-like growth factor I receptor signaling-overlapping or redundant pathways? Endocrinology 2000; 141: 1287-1288.

2. Nakae J, Kido Y, Accili D. Distinct and overlapping functions of insulin and IGF-I receptors Endocr Rev 2001; 22: 818-835.

3. Wood AW, Duan C, Bern HA. Insulin-like growth factor signaling in fish. Int Rev Cytol 2005; 243: 215-285.

4. Dupont J, LeRoith D. Insulin and insulin-like growth factor I receptors: similarities and differences in signal transduction. Horm Res 2001; 55: 22-26.

5. Valentinis B, Baserga R. IGF-I receptor signalling in transformation and differentiation. $\mathrm{Mol}$ Pathol 2001; 54: 133-137.

6. Abuzzahab MJ, Schneider A, Goddard A, Grigorescu F, Lautier C, Keller E et al. IGF-I receptor mutations resulting in intrauterine and postnatal growth retardation. $N$ Engl J Med 2003; 349: 2211-2222.

7. Denley A, Wang CC, McNeil KA, Walenkamp MJ, Van Duyvenvoorde $\mathrm{H}$, Wit JM et al. Structural and functional characteristics of the Val44Met insulin-like growth factor missense mutation: correlation with effects on growth and development. Mol Endocrinol 2005; 19: 711-721.

8. Kawashima Y, Kanzaki S, Yang F, Kinoshita T, Hanaki K, Nagaishi J et al. Mutation at cleavage site of insulin-like growth factor receptor in a short-stature child born with intrauterine growth retardation. J Clin Endocrinol Metab 2005; 90: 4679-4687.

9. Walenkamp MJ, Karperien M, Pereira AM, Hilhorst-Hofstee Y, Van Doorn J, Chen JW et al. Homozygous and heterozygous expression of a novel insulin-like growth factor-I mutation. $J$ Clin Endocrinol Metab 2005; 90: 2855-2864.

10. Woods KA, Camacho-Hubner C, Savage MO, Clark AJ. Intrauterine growth retardation and postnatal growth failure associated with deletion of the insulin-like growth factor I gene. N Engl J Med 1996; 335: 1363-1367.
11. Baker J, Liu JP, Robertson EJ, Efstratiadis A. Role of insulin-like growth factors in embryonic and postnatal growth. Cell 1993; 75: 73-82.

12. Liu JP, Baker J, Perkins AS, Robertson EJ, Efstratiadis A. Mice carrying null mutations of the genes encoding insulin-like growth factor I (Igf-1) and type 1 IGF receptor (Igf1r). Cell 1993; 75: 59-72.

13. Schlueter PJ, Royer T, Farah MH, Laser B, Chan SJ, Steiner DF et al. Gene duplication and functional divergence of the zebrafish insulin-like growth factor 1 receptors. FASEB J 2006; 20: 1230-1232

14. Maures T, Chan SJ, Xu B, Sun H, Ding J, Duan C. Structural, biochemical, and expression analysis of two distinct insulin-like growth factor I receptors and their ligands in zebrafish. Endocrinology 2002; 143: 1858-1871.

15. Pera EM, Wessely O, Li SY, De Robertis EM. Neural and head induction by insulin-like growth factor signals. Dev Cell 2001; 1: 655-665.

16. Richard-Parpaillon L, Heligon C, Chesnel F, Boujard D, Philpott A. The IGF pathway regulates head formation by inhibiting Wnt signaling in Xenopus. Dev Biol 2002; 244: 407-417.

17. Eivers E, McCarthy K, Glynn C, Nolan CM, Byrnes L. Insulin-like growth factor (IGF) signalling is required for early dorso-anterior development of the zebrafish embryo. Int $J$ Dev Biol 2004; 48: 1131-1140.

18. Serbedzija GN, Chen JN, Fishman MC. Regulation in the heart field of zebrafish. Development 1998; 125: 1095-1101.

19. Vincent AM, Feldman EL. Control of cell survival by IGF signaling pathways. Growth Horm IGF Res 2002; 12: 193-197.

20. Peruzzi F, Prisco M, Dews M, Salomoni P, Grassilli E, Romano G et al. Multiple signaling pathways of the insulin-like growth factor 1 receptor in protection from apoptosis. Mol Cell Biol 1999; 19: 7203-7215.

21. Resnicoff M, Abraham D, Yutanawiboonchai W, Rotman HL, Kajstura J, Rubin R et al. The insulin-like growth factor I receptor protects tumor cells from apoptosis in vivo. Cancer Res 1995; 55: 2463-2469.

22. Pelegri F. Maternal factors in zebrafish development. Dev Dyn 2003; 228: 535-554.

23. Wang ZQ, Fung MR, Barlow DP, Wagner EF. Regulation of embryonic growth and lysosomal targeting by the imprinted Igf2/Mpr gene. Nature 1994; 372: 464-467.

24. Brogiolo W, Stocker H, Ikeya T, Rintelen F, Fernandez R, Hafen E. An evolutionarily conserved function of the Drosophila insulin receptor and insulin-like peptides in growth control. Curr Biol 2001; 11: 213-221.

25. Dale L, Jones CM. BMP signalling in early Xenopus development. Bioessays 1999; 21: 751-760

26. Wilson SI, Edlund T. Neural induction: toward a unifying mechanism. Nat Neurosci 2001; 4 (Suppl): 1161-1168

27. Belo JA, Bachiller D, Agius E, Kemp C, Borges AC, Marques S et al. Cerberus-like is a secreted BMP and nodal antagonist not essential for mouse development. Genesis 2000; 26: $265-270$.

28. Jones Jl, Clemmons DR. Insulin-like growth factors and their binding proteins: biological actions. Endocr Rev 1995; 16: 3-34

29. Firth SM, Baxter RC. Cellular actions of the insulin-like growth factor binding proteins. Endocr Rev 2002; 23: 824-854.

30. Hsieh T, Gordon RE, Clemmons DR, Busby Jr WH, Duan C. Regulation of vascular smooth muscle cell responses to insulin-like growth factor (IGF)-I by local IGF-binding proteins. J Biol Chem 2003; 278: 42886-42892.

31. Hodge RD, D'Ercole AJ, O'Kusky JR. Insulin-like growth factor-I accelerates the cell cycle by decreasing $\mathrm{G} 1$ phase length and increases cell cycle reentry in the embryonic cerebral cortex. J Neurosci 2004; 24: 10201-10210.

32. Chen C, Jack J, Garofalo RS. The Drosophila insulin receptor is required for normal growth. Endocrinology 1996; 137: 846-856.

33. Shingleton AW, Das J, Vinicius L, Stern DL. The temporal requirements for insulin signaling during development in Drosophila. PLoS Biol 2005; 3: e289.

34. Kimmel CB, Ballard WW, Kimmel SR, Ullmann B, Schilling TF. Stages of embryonic development of the zebrafish. Dev Dyn 1995; 203: 253-310.

35. Prager D, Yamasaki H, Weber MM, Gebremedhin S, Melmed S. Human insulin-like growth factor I receptor function in pituitary cells is suppressed by a dominant-negative mutant. J Clin Invest 1992; 90: 2117-2122.

36. Li Q, Shirabe K, Kuwada JY. Chemokine signaling regulates sensory cell migration in zebrafish. Dev Biol 2004; 269: 123-136.

37. Chen MC, Gong HY, Cheng CY, Wang JP, Hong JR, Wu JL. Cloning and characterization of zfBLP1, a Bcl-XL homologue from the zebrafish, Danio rerio. Biochim Biophys Acta 2001; 1519: 127-133.

38. Li Y, Xiang J, Duan C. Insulin-like growth factor binding protein-3 (IGFBP-3) plays an important role in regulating pharyngeal skeleton and inner ear formation and differentiation. J Biol Chem 2005; 280: 3613-3620.

39. Hu M, Easter SS. Retinal neurogenesis: the formation of the initial central patch of postmitotic cells. Dev Biol 1999; 207: 309-321.

40. Gray M, Moens CB, Amacher SL, Eisen JS, Beattie CE. Zebrafish deadly seven functions in neurogenesis. Dev Biol 2001; 237: 306-323. 